\title{
AN X-RAY MICROSCOPIC STUDY OF THE VASA VASORUM OF THE NORMAL HUMAN ASCENDING AORTA
}

\author{
BY \\ JOHN A. CLARKE \\ From the Department of Anatomy, University of Glasgow
}

Received April 22, 1964

The first observation on the vasa vasorum of the aortic wall is attributed to Willis (Haller, 1757). In a review of previous investigations Ramsey (1936), recording the descriptions of the principal nineteenth century investigators (Risse, 1843; Gimbert, 1865; Plotnikow, 1884), showed that interpretations of injected and routine histological specimens of the aortic wall differed on the depth the intramural vessels penetrated.

From an examination of animal aortæ injected with indian ink, Woodruff (1926) concluded that the aortic vasa arose from collateral branches of the aorta to be distributed to the adventitia and inner media. Robertson (1929), injecting human and animal aortæ with coloured cellulose, demonstrated networks of adventitial vessels and concluded that the outer third of the media in the human aorta was vascularized. By injecting the aortic wall with Higgins ink and clearing in glycerine or by the Spalteholz method, Winternitz, Thomas, and LeCompte (1938) revealed vascular patterns in the outer media of the human and animal arterial wall, and demonstrated intimal vascularization in atheromatous plaques.

Injection studies with stained fat (Celestino da Costa, 1947), stained red cells (O'Neill, 1947), and potassium dichromate and lead acetate (Williams, 1948), showed capillary plexuses in the walls of large vessels in animals. Geiringer (1951), from an examination of frozen sections of human aorta, concluded that the normal aortic intima was avascular, only acquiring a secondary blood supply if it attained a critical thickness of $0.5 \mathrm{~mm}$.

The introduction of microradiographic techniques in arteriography (Barclay, 1947) permitted the study of the microcirculation without routine histological preparation of tissues. de Sousa and Alvares (1960) and Nylander and Olerud (1960), employing microradiography, demonstrated the vasa vasorum of the aorta and inferior vena cava in the dog, revealing the adventitial arteriolar plexus and the patterns of distribution to the inner layers of the vessel wall.

This work presents an account of the examination of vascular patterns and distribution in the ascending aortic wall, using the Coslett-Nixon X-ray Projection Microscope. This method gives an opportunity of observing the vascular architecture in full thickness arterial wall, without histological preparation, in contrast to routine methods used by previous investigators.

\section{MATERIAL AND Methods}

Fifty normal ascending aortæ were examined, within eight hours of death, from hearts equally distributed in five-yearly groups between the ages of 15 and 80 years.

The microcirculation in the aortic wall was demonstrated by injecting micropaque at physiological pressures: the arterial side through the ascending aorta; the venous side through the coronary sinus.

$\mathrm{X}$-ray projection micrographs of full thickness aortic wall and $1 \mathrm{~mm}$. thick sections were taken on Ilford Contrasty Plates with an exposure time of 10 minutes. The microscope was operated at $15 \mathrm{kV}$ and 40 micro-amps, with a copper target providing the X-radiation. 


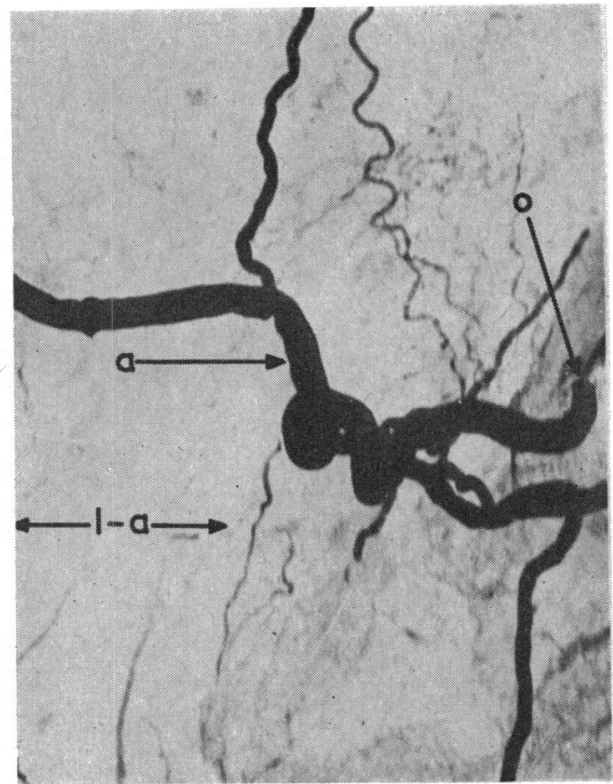

FIG. $1^{*}$.

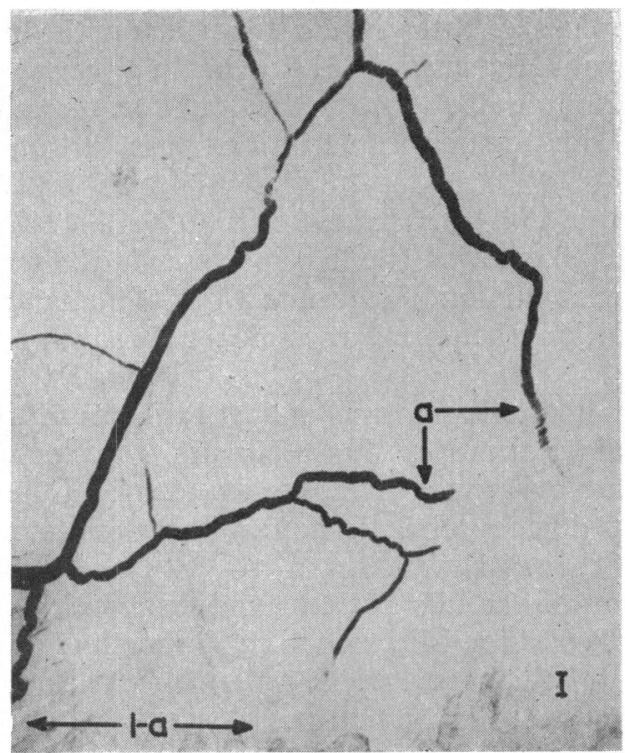

FIG. 3.

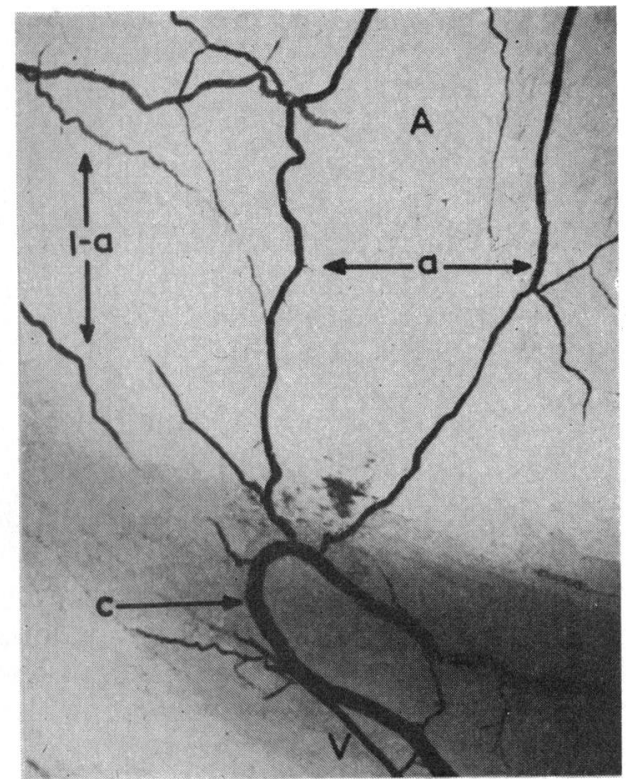

FIG. 2.

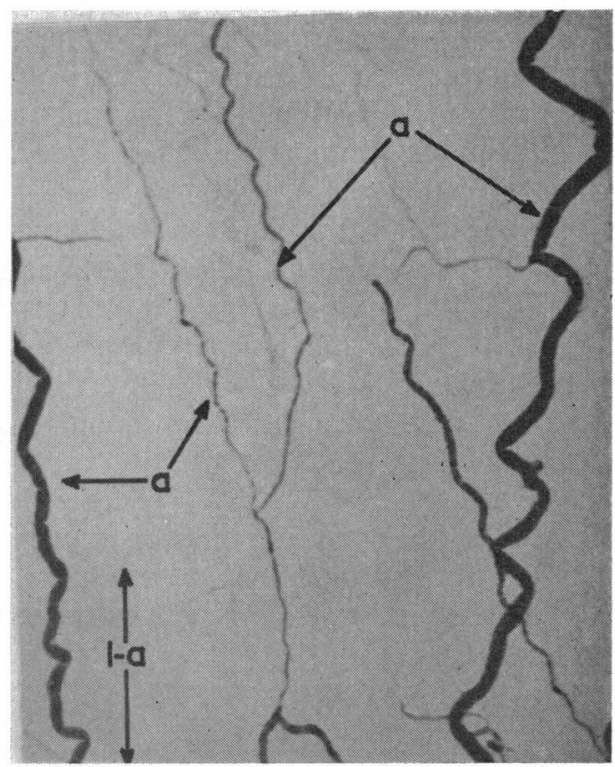

FIG. 4

FIG. 1.-Micrograph showing adventitial arterioles (a) arising from right coronary ostium (o). ( $\times 40$.

FIG. 2.-Micrograph showing origin of adventitial arterioles (a) from terminal ventricular branch of left coronary artery (c). Ventricle (V). Aorta (A). ( $\times 20$.

FIG. 3.-Micrograph showing termination of arterial supply (a) from coronary ostia, $1 \mathrm{~cm}$. proximal to innominate artery origin $(I)$. $(\times 40$. $)$

FIG. 4.-Micrograph showing longitudinal, coiled arterioles in aortic adventitia $(a) .(\times 20$.

* All micrographs are of full thickness specimens except in Fig. 5-6, 9-10, and 13-14. Long axis of aorta (1-a). 


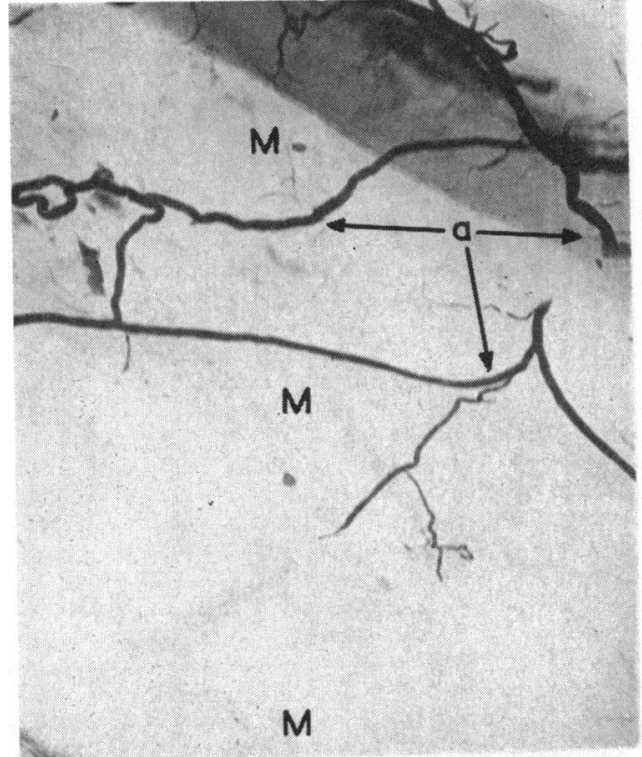

FIG. 5.

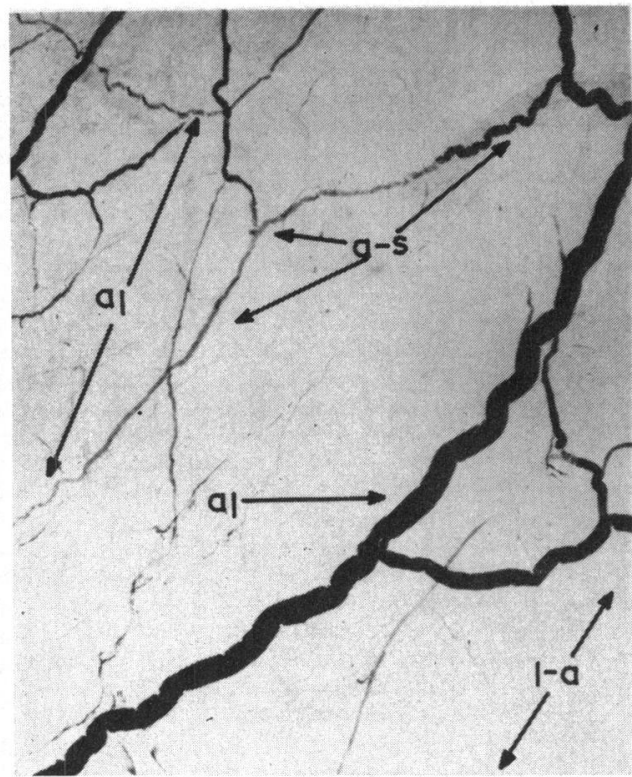

FIG. 7.

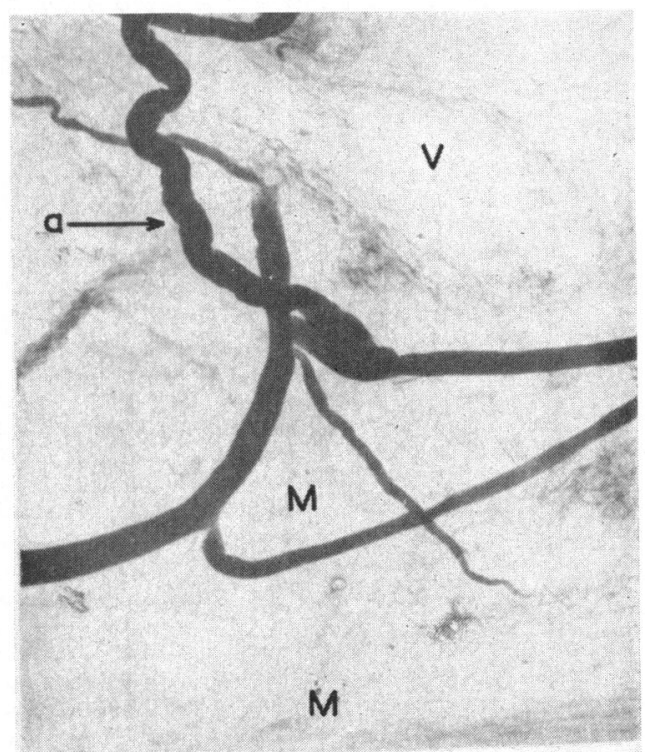

FIG. 6.

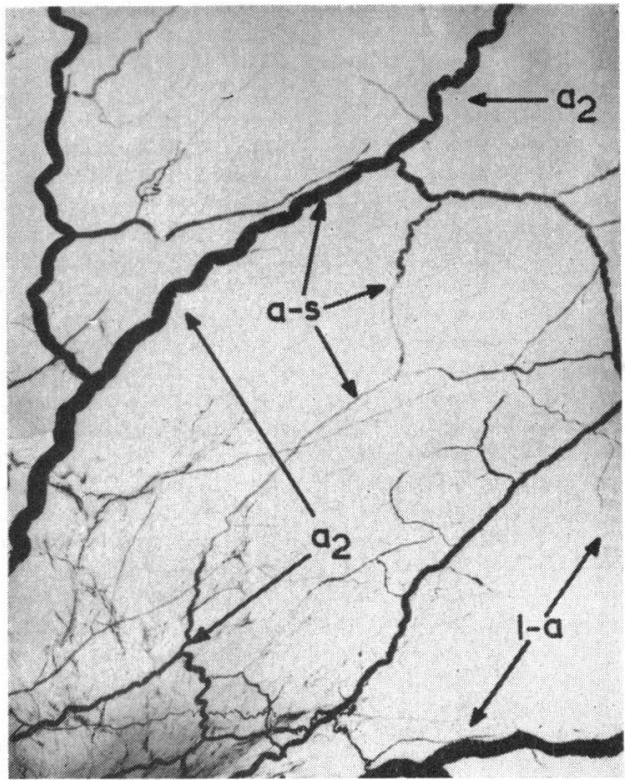

FIG. 8.

FIG. 5.-Micrograph of $1 \mathrm{~mm}$. longitudinal section of aortic wall. Note adventitial arterioles (a) penetrating outer two-thirds of media $(M)$. $(\times 30)$

Fig. 6.-Micrograph of $1 \mathrm{~mm}$. transverse section aorta. Note coiling of arteriole (a) penetrating adventitia (V) to bifurcate in outer third media $(\mathrm{M}) . \quad(\times 50$.

FIG. 7 and 8.-Micrographs showing looser and tighter coiling of adventitial arterioles (al: a2). Specimens from cases aged 30 and 55 years respectively. Anastomoses between longitudinal adventitial arterioles (a-s). (×30.) 
FiG. 9.
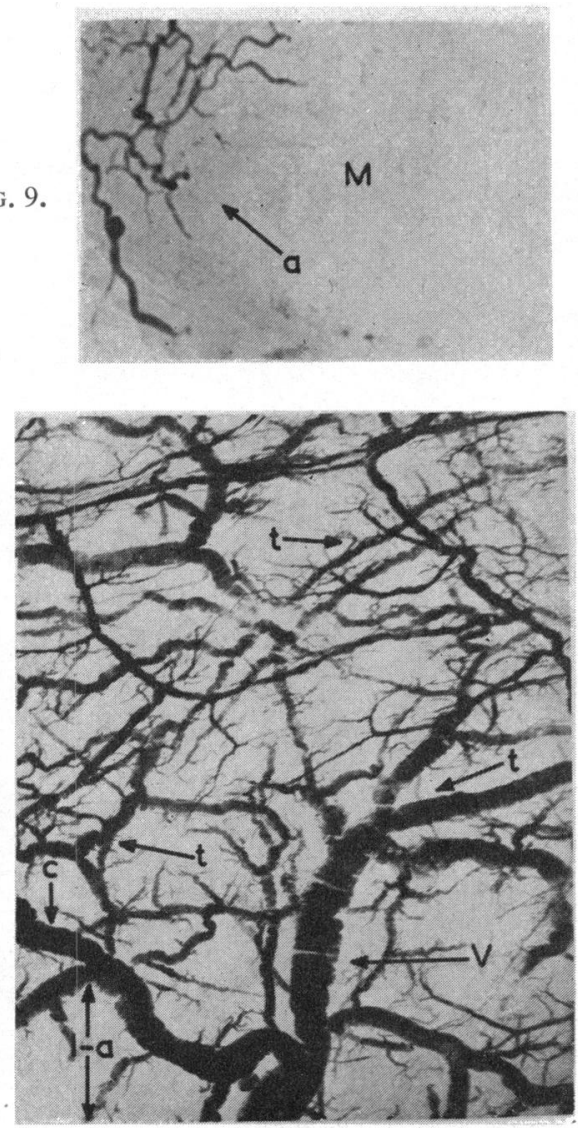

FIG. 11.

FIG. 13.

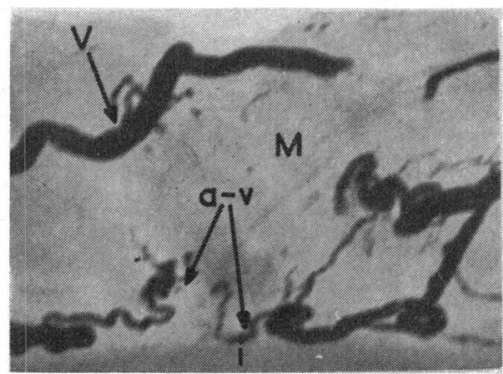

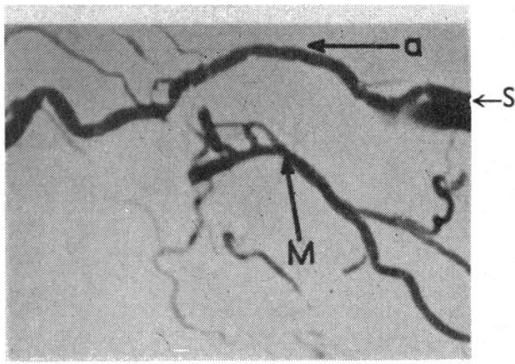

FIG. 10

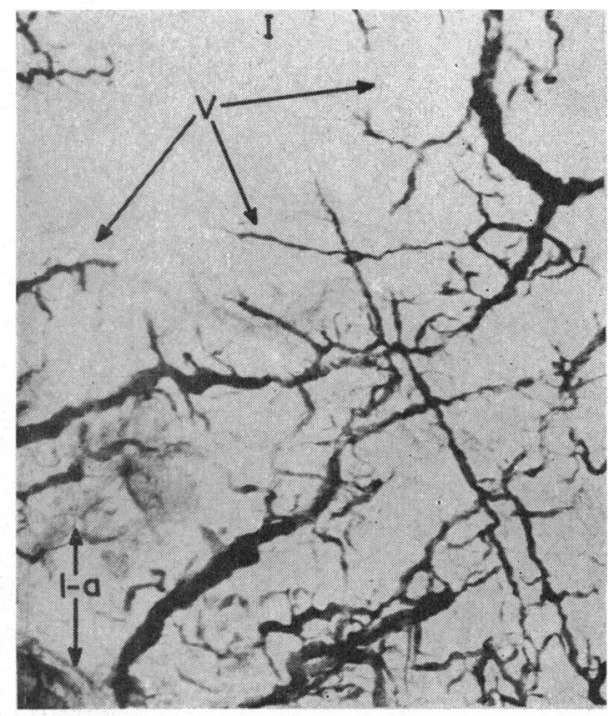

FIG. 12.

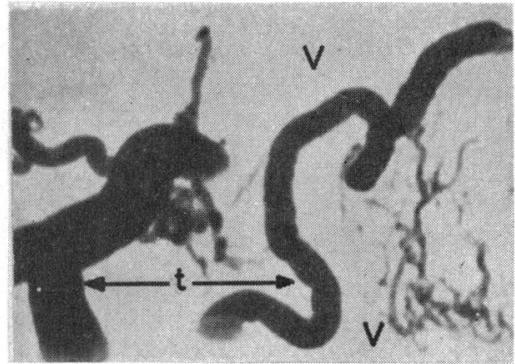

FIG. 14.

FIG. 9.-Micrograph of $1 \mathrm{~mm}$. transverse section aorta. Note terminal arteriolar and capillary branches (a) in middle third of media (M). ( $\times 50$.

FIG. 10.-Micrography of $1 \mathrm{~mm}$. longitudinal section of aorta, showing intimal stoma (S). Note intimal arteriole (a); arterioles in media (M). ( $\quad$ 50.)

FIG. 11.-Micrograph showing adventitial venous plexus. Note terminal venous channel (V) receiving tributaries $(t)$. Cross anastomotic channel $(c) .(\times 35$.)

FIG. 12.-Micrograph showing origin of adventitial venous plexus (V) $1 \mathrm{~cm}$. proximal to innominate artery origin (I). ( $\times 30$.

FIG. 13.-Micrograph of $1 \mathrm{~mm}$. longitudinal section aorta. Note intima (i): inner third media (M): venous tributaries in inner third media $(\mathrm{V})$ : arteriovenous anastomoses $(\mathrm{a}-\mathrm{v}) .(\times 65$.

FIG. 14.-Micrograph of $1 \mathrm{~mm}$. transverse section aorta, showing deep layers of adventitia (V). Note venous tributaries $(t)$ traversing aortic wall. $(\times 85$. 


\section{OBSERVATIONS}

From an examination of the micrographs it was concluded that the arterial supply to the ascending aortic wall originated from the coronary ostia and the terminal ventricular branches of the left coronary artery (Fig. 1-3).

It was found that the right and left coronary arteries distributed longitudinal arteriolar channels, $100 \mu$ in diameter, to the aortic adventitia (Fig. 1, 3, and 4). Frequent anastomoses between arterioles occurred (Fig. 7-8).

From the adventitial plexus, arterioles $80 \mu$ in diameter (Fig. 5-6) penetrated the deep layers of the adventitia, bifurcated, and formed a secondary plexus of vessels, $10-20 \mu$ in diameter, in the outer two-thirds of the media (Fig. 9).

It was evident from the micrographs that the adventitial arterioles and their immediate branches showed coiling which was most marked on the convex side of the ascending aorta (Fig. 7-8).

The terminal branches of the left coronary artery were distributed to the base of the aorta and attachment of the aortic valve. These arteries showed coiling, were $50 \mu$ in diameter at their origin, and formed an irregular network in the adventitia before penetrating the outer two-thirds of the media (Fig. 2).

From an examination of the micrographs showing the venous side of the microcirculation, it was concluded that there was a dense plexus of veins in the adventitial layer of the aorta, which commenced $1 \mathrm{~cm}$. proximal to the aortic arch and drained into longitudinal venous channels situated predominantly on the concave side of the aortic wall. Arranged approximately parallel and showing cross anastomoses, these longitudinal channels were $140 \mu$ in diameter and drained into tributaries of the ventricular coronary veins at the base of the aorta (Fig. 11-12).

The tributaries of the adventitial venous network originated in the aortic wall at the junction of the intimal and medial layers, thus appearing closer to the aortic lumen than the arteries. Coalescing in an irregular pattern, these tributaries traversed the thickness of the aortic wall to drain into the adventitial venous network (Fig. 13, 14).

\section{Discussion}

The vasa vasorum are of importance since they supply part of the oxygen and nutrition for the arterial wall.

Winternitz et al. (1938), concluded that while the intima was only vascularized in "arteriosclerosis" the media contained "large sinusoids" which were venous vasa. Woerner (1959) examined serially-cut $400 \mu$ sections of the ascending aorta and reported "a vascular area in the inner half of the wall" in one specimen.

In this series it was confirmed that the intima in the normal ascending aorta was avascular. Two specimens, however, showed intimal stomata from which a small artery, $80 \mu$ in diameter, arose, pierced the intima without branching, and arborized with the arterial plexus in the media (Fig. 10).

Examination of the vascular patterns in the adventitia and media showed that the venous and arterial sides of the microcirculation could be differentiated in vessels with a diameter greater than $20 \mu$.

The coiling of the arterioles in the adventitia and outer third of the media was interpreted as a defence mechanism against excessive stretch during systole.

It is evident from the micrographs (Fig. 13) that tortuous vessels $25-30 \mu$ in diameter lie at the junction of the media and intima. These were only found after the venous side of the circulation had been injected. It is suggested that they correspond to the venous vasa described by Winternitz et al.

It was concluded, therefore, that since small arterioles $20 \mu$ in diameter could be identified in the middle layer of the media, the arteriovenous anastomoses occurred in the inner third of the media (Fig. 13). With age, there was no evidence of an increase in arterial vascularity, but the adventitial arterioles were more tightly coiled in specimens from persons over 50 years of age (Fig. 7-8). 


\section{SUMMARY}

The vasa vasorum of normal adult, post-mortem, ascending aortæ were injected with micropaque to demonstrate the arterial and venous sides of the microcirculation. X-ray projection micrographs were taken with the Coslett-Nixon X-ray Microscope.

It was found that the arteries originated from the coronary ostia and terminal ventricular branches of the left coronary artery, to be distributed in coiled arteriolar plexuses to the adventitia and outer two-thirds of the media. Commencing in the inner third of the media, the veins traversed the thickness of the aortic wall to drain into longitudinal adventitial venous channels, which were tributaries of the ventricular coronary veins. The intima was avascular, except in two cases where intimal stomata were shown to distribute arterioles to the arterial plexus in the media.

It was concluded that the coiling of the adventitial arterioles was a defence mechanism against the stretch effect of systole, and that the arteriovenous anastomoses occurred in the inner third of the media.

I am grateful to Professor G. M. Wyburn for his interest in this study.

I am also grateful to Professor D. F. Cappell, Pathology Department, Glasgow University, and Dr. R. I. Shaw Dunn, Pathology Department, Law Hospital, whose co-operation enabled this work to be done.

I am indebted to the Medical Research Council whose aid enabled the purchase of the X-ray microscope.

\section{REFERENCES}

Barclay, A. E. (1947). Micro-arteriography. Brit.J. Radiol., 20, 394.

Celestino da Costa, J. (1947). Les vasa-vasorum de l'aorte. Une methode pour leur étude. Arch. Portugaises Biol., 8, Suppl. 14.

de Sousa, A., and Alvares, L. (1960). Microangiographic study of the vasa vasorum of the thoracic aorta. Radio$\log y, 75,91$.

Geiringer, E. (1951). Intimal vascularization and atherosclerosis. J. Path. Bact., 63, 201.

Gimbert, J. L. (1865). Structure et texture des artères. Thèse de Paris, No. 181.

Haller, A. (1757). Elementa Physiologiae Corporis Humani. Bousquet, Lausanne, Vol. 1, pp. 67-89.

Nylander, G., and Olerud, S. (1960). The distribution of the vasa vasorum in the abdominal aorta and the vena cava inferior in dogs. Angiology, 11, 522.

O'Neill, J. F. (1947). The effects on venous endothelium of alterations in blood flow through the vessels in vein walls, and the possible relation to thrombosis. Ann. Surg., 126, 270.

Plotnikow, V. (1884). Untersuchungen über die Vasa vasorum. Inaug. Diss. Dorpat.

Ramsey, E. M. (1936). Studies in the pathology of vascular disease I. Nutrition of the blood vessel wall. Review of the literature. Yale J. Biol. Med., 9, 14 .

Risse, A. (1843), Observationes quædam de arteriarum statu normali atque pathologico. Inaug. Diss., Regiomonti Pr., E. J. Dalkowski.

Robertson, H. F. (1929). Vascularization of the thoracic aorta. Arch. Path., 8, 881.

Williams, T.W. (1948). The visualization of vertebrate capillary beds by intravascular precipitation of lead chromate. Anat. Rec., 100, 115.

Winternitz, M. C., Thomas, R. M., and LeCompte, P. M. (1938). The Biology of Arteriosclerosis. Charles C. Thomas, Springfield, Illinois.

Woerner, C. A. (1959). Vasa vasorum of arteries, their demonstration and distribution. In The Arterial Wall ed. A. I. Lansing, p. 1. William and Wilkins, Baltimore.

Woodruff, C. E. (1926). Studies on the vasa vasorum. Amer. J. Path., 2, 567. 